tion method which requires no specialized equipment has proved to be the most satisfactory for our purpose.

Shaffer and Critchfield ${ }^{3}$ used silicotungstic and phosphomolybdic acid in the presence of barium to precipitate polyglycols of the 'Carbowax' type having a mean molecular weight of the order of 6,000. After a long tedious procedure, the polyglycol is finally determined by a gravimetric procedure for silicotungstic acid and by a colorimetric method for phosphomolybdic acid. This method, however, is considered too exacting for routine determinations. The following simplified procedure is based on similar principles and is in course of adoption in our laboratories as a standard method for the determination of non-ionic detergents.

The reagents required are : $(a)$ detergent solution of known concentration; (b) hydrochloric acid solution, 1 vol. of the concentrated acid diluted to 4 vol. with distilled water; (c) barium chloride, $10 \mathrm{gm}$. $\mathrm{EaCl}_{2} \cdot 2 \mathrm{H}_{2} \mathrm{O}$ dissolved in $100 \mathrm{ml}$. distilled water ; (d) phosphomolybdic acid (B.D.H.), $10 \mathrm{gm}$. $\left(\mathrm{P}_{2} \mathrm{O}_{5} .2 \mathrm{OMoO}_{3} .5 \mathrm{IH}_{2} \mathrm{O}\right)$ dissolved in $100 \mathrm{ml}$. distilled water.

Sulphates, if present, interfere with the determination and must be removed by treatment with barium chloride solution before the following procedure. An aliquot part of solution (a) containing a known amount of detergent (usually not more than 100 mgm.) is pipetted into a $250-\mathrm{ml}$. beaker, to which is added, in the following order, $5 \mathrm{ml}$. each of hydrochloric acid (solution $b$ ), barium chloride (solution c) and phosphomolybdic acid (solution $d$ ); the contents are diluted to $150 \mathrm{ml}$. with distilled water. The yellowish-green precipitate formed is flocculated by raising the mixture to the boil; the beaker is then covered and allowed to stand overnight (18 hours). The precipitate is filtered through a tared No. 4 sintered glass crucible (previously heated for 15 minutes at $100^{\circ} \mathrm{C}$. and cooled in a desiccator) washed with a minimum of $100 \mathrm{ml}$. of distilled water and dried at $100^{\circ} \mathrm{C}$. to a constant weight. After two 1-hour periods substantially no change in weight is found.

This procedure establishes the ratio, weight of complex to weight of detergent, for the particular detergent preparation under test.

The results from four individual sets of experiments by different operators are given in the accompanying table.

\begin{tabular}{|c|c|c|c|c|c|c|}
\hline \multirow{2}{*}{$\begin{array}{l}\text { Wt. of ethyl- } \\
\text { ene oxide } \\
\text { condensation } \\
\text { product } \\
\text { (gm.) }\end{array}$} & \multicolumn{5}{|c|}{ Weight of complex (gm.) } & \multirow{2}{*}{$\begin{array}{l}\text { Mean } \\
\text { deviation } \\
\text { expressed } \\
\text { as \% of } \\
\text { mean }\end{array}$} \\
\hline & Set 1 & Set 2 & Set 3 & Set 4 & Mean & \\
\hline $\begin{array}{l}0.012 \\
0.024 \\
0.048 \\
0.096\end{array}$ & $\begin{array}{l}0.0336 \\
0.0695 \\
0.1458 \\
0.2824\end{array}$ & $\begin{array}{l}0.0338 \\
0.0706 \\
0.1458 \\
0.2901\end{array}$ & $\begin{array}{l}0.0354 \\
0.0706 \\
0.1451 \\
0.2897\end{array}$ & $\begin{array}{l}0.0358 \\
0.0728 \\
0.1436 \\
0.2894\end{array}$ & $\begin{array}{l}0.0347 \\
0.0716 \\
0.1451 \\
0.2876\end{array}$ & $\begin{array}{l}2 \cdot 5 \\
1 \cdot 8 \\
0 \cdot 5 \\
0 \cdot 9\end{array}$ \\
\hline
\end{tabular}

The reproducibility of the method is thus reasonably good.

On plotting weight of complex against weight of detergent, a rectilinear graph is obtained. This is used as a calibration graph for this particularr detergent. Samples or solutions of this same detergent, of unknown coneentration, are then analysed by following the procedure detailed above and interpreting the results obtained with the aid of the calibration graph.
We are glad to acknowledge the co-operation of Mr. N. Strafford, chief analyst of the Dyestufis Division.

J. Oliver

C. Preston

Imperial Chemical Industries, Ltd.,

Dyehouse Laboratories,

Hexagon House,

Manchester 9 .

Feb. 9 .

${ }^{1}$ Barr. T., Oliver, T., and Stubbings, W. v., J. Soc. Chem. Indust., 67, 45 (1948)

'Epton, S. R., Nature, 160, 795 (1947).

${ }^{3}$ Shaffer, C. B., and Critchfield, F. H., Indust. Eng. Chem., Anul. Ed., 19, $32(1947)$

\section{Heterocyclic Compounds from Schiff's Bases}

BENZIMIDAzoles have been prepared by oxidation of a mixture of an o-phenylene diamine and an aldehyde with cupric salts ${ }^{1}$ (for example, cupric acetate), and it has been pointed out ${ }^{2}$ that the reastion proceeds by the oxidative ring closure of the mono-Schiff's bases first obtained:<smiles>[R]C=NC(C)=C(C)N</smiles>
oxidation<smiles>[R]c1nc(C)c(C)[nH]1</smiles>

With certain nitro-substituted o-phenylene diamines. this method has not been entirely satisfactory in our hands, and we have attempted to close the ring of such Schiff's bases by means of reagents other than cupric salts. We have found lead tetra-acetate an excellent reagent for this purpose, giving high yields of 2 -aryl benzimidazoles, and the reaction proceeding very rapidly.

We have extended the method to the synthesis of 2-aryl benzoxazoles by showing that the Sehiff's bases of $o$-aminophenol are rapidly converted to the ring compounds by means of this reagent. In this manner, for example, the following compounds have been prepared: 2-(p-nitrophenyi $\rangle$-benzoxazole, m.p. 267$68^{\circ}$ (found: $\mathrm{N}, 11 \cdot 77 ; \mathrm{C}_{13} \mathrm{H}_{8} \mathrm{O}_{3} \mathrm{~N}_{2}$ requires $\mathrm{N}, 11 \cdot 66$ per cent) ; 2-( $m$-nitrophenyl)-benzoxazole, m.p. 211$212^{\circ}$ (found: $\mathrm{N}, \mathrm{II} \cdot 8 ; \mathrm{C}_{13} \mathrm{H}_{8} \mathrm{O}_{3} \mathrm{~N}_{2}$ requires $\mathrm{N}, 11 \cdot 66$ per cent); and 2 -( $p$-chlorophenyl)-benzoxazole, m.p. $152^{\circ}$ (found : $\mathrm{N}, 6 \cdot 15 ; \mathrm{Cl}, 15 \cdot 6 ; \mathrm{C}_{13} \mathrm{H}_{8} \mathrm{ONCl}$ requires $\mathrm{N}, 6 \cdot 1$; $\mathrm{Cl}, \mathbf{1 5} \cdot 45$ per cent).

The reaction may be conducted in glacial acetic acid or in benzene. In the latter case it is only necessary to add the calculated amount of lead tetraacetate to the Schiff's base dissolved or suspended in the solvent, when the mixture becomes warm, and, after the reaction is complete, the benzoxazole may be isolated by conventional methods. Working on 1/100 molar scale, the yields so far obtained appear in many cases to be of the order of 80 per cent of the theoretical.

This method of ring closure is being studied and extended. The results will be published in greater detail elsewhere.

Research Laboratory,

\section{F. F. STEPHENS}

British Chemicals and Biologicals, Ltd., Loughborough.

Feb. 7.

Weidenhagen, Ber., 69, 2263 (1936).

${ }^{2}$ Weidenhagen and Weedon, Ber., 71, 2347 (1938). 